\title{
Vitamin D Promotes Pneumococcal Killing and Modulates Inflammatory Responses in Primary Human Neutrophils
}

\author{
Karthik Subramanian ${ }^{a}$ Peter Bergman ${ }^{b, c}$ Birgitta Henriques-Normark ${ }^{a, c}$ \\ ${ }^{a}$ Department of Microbiology, Tumor and Cell Biology, Karolinska Institutet, Stockholm, ${ }^{\mathrm{b}}$ Department of Laboratory \\ Medicine, Clinical Microbiology, Huddinge, Karolinska Institutet, Stockholm, and ${ }^{\mathrm{C} C l i n i c a l}$ Microbiology, Karolinska \\ University Hospital, Stockholm, Sweden
}

\section{Keywords}

Vitamin D · Neutrophils · Streptococcus pneumoniae . Pneumococci · Alpha-defensins · Human neutrophil peptides $\cdot$ Immunomodulation · Suppressor of cytokine signaling $\cdot$ SOCS- $1 \cdot$ SOCS-3 $\cdot$ Interleukin-4

\begin{abstract}
Streptococcus pneumoniae is a major human pathogen and a leading cause of pneumonia, septicemia, and meningitis worldwide. Despite clinical studies linking vitamin $D$ deficiency and pneumonia, molecular mechanisms behind these observations remain unclear. In particular, the effects of vitamin D on neutrophil responses remain unknown. Using pneumococcal strains, primary neutrophils isolated from human blood, and sera from patients with frequent respiratory tract infections (RTIs), we investigated the effects of vitamin D on neutrophil bactericidal and inflammatory responses, including pattern recognition receptors, antimicrobial peptides, and cytokine regulation. We found that vitamin D upregulated pattern recognition receptors, TLR2, and NOD2, and induced the antimicrobial human neutrophil peptides (HNP1-3) and LL-37, resulting in increased killing of pneumococci in a vitamin $\mathrm{D}$ receptor-dependent manner.
\end{abstract}

\section{KARGER}

(C) 2017 S. Karger AG, Basel

E-Mail karger@karger.com

www.karger.com/jin
Antibodies targeting HNP1-3 inhibited bacterial killing. Vitamin D supplementation of serum from patients with bacterial RTIs enhanced neutrophil killing. Moreover, vitamin D lowered inflammatory cytokine production by infected neutrophils via IL-4 production and the induction of suppressor of cytokine signaling (SOCS) proteins SOCS-1 and SOCS-3, leading to the suppression of NF-KB signaling. Thus, vitamin D enhances neutrophil killing of S. pneumoniae while dampening excessive inflammatory responses and apoptosis, suggesting that vitamin $\mathrm{D}$ could be used alongside antibiotics when treating pneumococcal infections.

(c) 2017 S. Karger AG, Basel

\section{Introduction}

Streptococcus pneumoniae (the pneumococcus) is a common commensal in the human nasopharynx, but also a major cause of otitis, sinusitis, pneumonia, septicemia, and meningitis. Around 1.6 million individuals die from pneumococcal infections annually, of which $50 \%$ are children younger than 5 years of age [1]. Pneumococci express several virulence factors such as the polysaccharide capsule $[2,3]$ to evade host immune responses. 
Neutrophils are key immune cells recruited to the site of infection and play an important role during pneumococcal colonization and pneumonia in mice $[4,5]$. Neutrophils contain a plethora of antimicrobial peptides (AMPs) stored in their granules [6]. Alpha-defensins are a subfamily of AMPs comprising 6 peptides [7], 4 of which are expressed by human neutrophils, designated human neutrophil peptides (HNP1-4). Although neutrophil function is vital for an effective immune response, prolonged activation of neutrophils promotes inflammation by secreting excessive proinflammatory cytokines, such as IL-6, IL-8, IL-12, and TNF- $\alpha$, resulting in tissue damage.

Vitamin D deficiency has been associated with disease severity in community acquired pneumonia [8] and other respiratory tract infections (RTIs) [9], and vitamin D supplementation has been beneficial in patients with RTIs [10]. Vitamin D is naturally synthesized in the skin from 7-dehydrocholesterol upon exposure to ultraviolet $\mathrm{B}$ radiation from the sun. To become activated, the precursor $25(\mathrm{OH}) \mathrm{D}_{3}$ is hydroxylated by the mitochondrial 1- $\alpha$ hydroxylase enzyme (CYP27B1) to yield the bioactive form, $1,25(\mathrm{OH})_{2} \mathrm{D}_{3}$. Active vitamin $\mathrm{D}_{3}\left(1,25(\mathrm{OH})_{2} \mathrm{D}_{3}\right)$ binds to the vitamin D receptor (VDR) [11]. Vitamin D has been shown to mediate immunosuppressive effects on the human immune system by affecting human monocytes/macrophages [12], dendritic cells [13], and T cells [14]. Clinical associations have been found between vitamin D deficiency and pneumonia [15]. However, mechanistic insight into its effects on neutrophils and on pneumococcal infections is unknown.

Here we investigated the effects of vitamin $\mathrm{D}$ on human neutrophil responses to pneumococci. We show that vitamin $\mathrm{D}$ induces the production of AMPs while dampening inflammatory responses, and provide mechanistic insight to these findings. Since mouse and human neutrophils differ profoundly in their granular composition of AMPs and vitamin D regulation, we used human neutrophils in this study [16-18].

\section{Materials and Methods}

\section{Bacterial Strains and Culture}

The S. pneumoniae strain T4 (TIGR4; ATCC BAA-334) of serotype 4 [19], its isogenic capsular mutant strain T4R [20], and strain D39 of serotype 2 [21] were used. Pneumococci and the Staphylococcus aureus strain 8325-4 were grown overnight on blood agar plates at $37^{\circ} \mathrm{C}$ and $5 \% \mathrm{CO}_{2}$ to $\mathrm{OD}_{620}=0.5 \mathrm{in} \mathrm{C+Y} \mathrm{me-}$ dium (Karolinska University Laboratories). Pneumococci were heat-killed by incubation at $65^{\circ} \mathrm{C}$ for $1 \mathrm{~h}$.
Isolation of Primary Neutrophils and Patient Sera

Peripheral blood was collected from healthy donors at Karolinska University Hospital, Stockholm. Blood was provided anonymously, hence informed consent was not required. Blood was diluted in PBS and layered on to Biocoll (Biochrom AG) separating solution and centrifuged at 1,200 rpm for $20 \mathrm{~min}$. Upon removing the plasma and mononuclear cell layer, ammonium chloride lysis buffer (Karolinska University Laboratories) was added to the granulocyte-erythrocyte pellet to lyse the erythrocytes, and incubated on ice for $15 \mathrm{~min}$. The granulocytes were subsequently washed twice with PBS. Neutrophils were enriched using the EasySep human neutrophil enrichment kit (StemCell Technologies) by negative selection according to the manufacturer's instructions. Neutrophils were defined as CD66b+CD16+. The purity of the neutrophils postenrichment was approximately $99 \%$ (see online suppl. Fig. S1A-C; see www.karger.com/doi/10.1159/000455969 for all online suppl. material). Neutrophils were resuspended in RPMI 1640 medium (+L-glutamine; Invitrogen) supplemented with $2 \%$ heat-inactivated fetal bovine serum (Invitrogen).

Sera collected in a randomized clinical trial by Bergman et al. [10] were used. The inclusion criteria for the participants were age 18-75 years and increased susceptibility to bacterial RTIs ( $>42$ days with symptoms from RTI during a 12-month period prior to study inclusion), but without a defined immunological diagnosis. The samples were chosen to reflect a range of vitamin D-levels, spanning from 11 to $123 \mathrm{nM}$ (mean $84 \mathrm{nM}$ ). Exclusion criteria were prophylactic treatment with antibiotics, history of hypercalcemia or stones in the urinary tract, sarcoidosis, ongoing supplementation with vitamin $\mathrm{D}_{3}$ exceeding $400 \mathrm{IU} /$ day, HIV-infection, and pregnancy. All experiments and procedures were performed according to the declaration of Helsinki and to current guidelines at Karolinska Institutet.

\section{Stimulation and Infection of Neutrophils}

Neutrophils $\left(0.5 \times 10^{6}\right)$ were pretreated with vitamin D $\left(1,25(\mathrm{OH})_{2} \mathrm{D}_{3} ; 100 \mathrm{nM}\right)$, the proform of vitamin $\mathrm{D}\left(25(\mathrm{OH}) \mathrm{D}_{3} ; 100\right.$ $\mathrm{nM})$ or vehicle ( $0.1 \%$ ethanol) diluted in RPMI 1640 medium for $2 \mathrm{~h}$ in 96 -well plates. The vitamin $\mathrm{D}$ concentration was chosen to reflect the physiological range of concentrations found in vitamin $D$-sufficient adults [22]. For infection, neutrophils were incubated with pneumococci at a multiplicity of infection of 0.1 for $4 \mathrm{~h}$. The infection dose was chosen to induce minimal cell death as confirmed by the lactase dehydrogenase assay (see online suppl. Fig. S1D). In some experiments, pneumococcal peptidoglycan (PGN; $10 \mu \mathrm{g} / \mathrm{mL}$ ) was added together with vitamin D. For HNP1-3 blocking experiments, neutrophils were pretreated with $0.5 \mu \mathrm{g} / \mathrm{mL}$ a-HNP1-3 (clone D21; Hycult Biotech) for $1 \mathrm{~h}$ prior to stimulation. Stimulation with $25(\mathrm{OH}) \mathrm{D}_{3}$ was preceded by incubation with human IFN- $\gamma(10 \mathrm{ng} / \mathrm{mL})$ for $2 \mathrm{~h}$. The VDR antagonist (iVDR) ZK159222 was used at $0.5-1 \mu \mathrm{M}$ to block VDR signaling.

\section{Statistical Analysis}

Data are presented as the mean \pm SEM for $\geq 3$ donors unless specified otherwise. Statistical analysis was performed using the GraphPad Prism 5.0 software (GraphPad, La Jolla, CA, USA). Data were analyzed using the nonparametric Mann-Whitney test and considered significant at $p<0.05$. To analyze the effect of 2 variables, ANOVA with Bonferroni post hoc test was used and considered significant at $p<0.05$.

Further experimental details are provided in online supplementary Methods.
376

J Innate Immun 2017;9:375-386

DOI: 10.1159/000455969
Subramanian/Bergman/

Henriques-Normark 


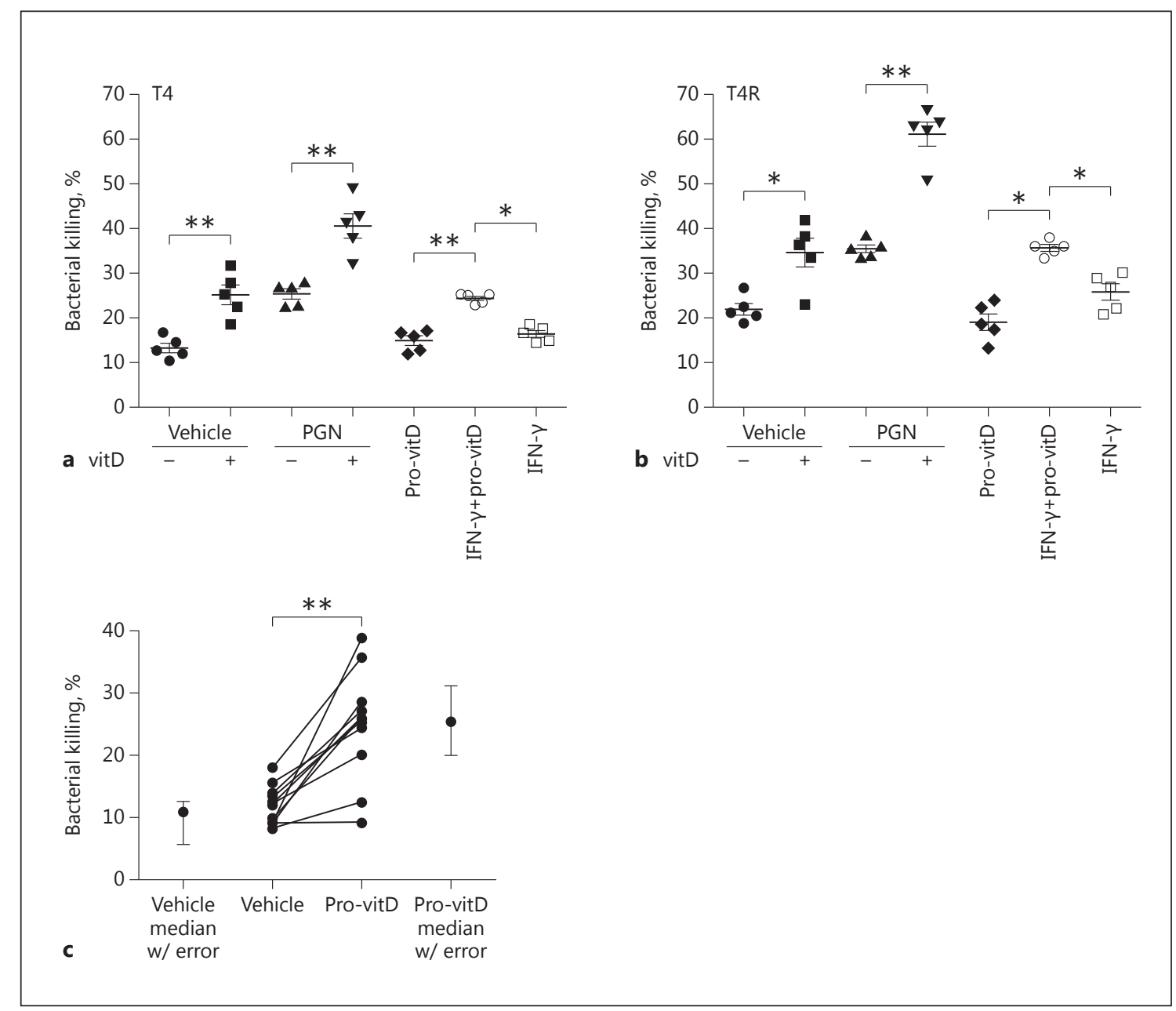

Fig. 1. Vitamin D enhances neutrophil killing of S. pneumoniae. a, b Neutrophils were stimulated with vehicle $(0.1 \%$ ethanol) or 100 nM of $1,25(\mathrm{OH})_{2} \mathrm{D}_{3}$ (vitD) with or without pneumococcal PGN (10 $\mu \mathrm{g} / \mathrm{mL}$ ) for $6 \mathrm{~h}$. The prohormone, $25(\mathrm{OH}) \mathrm{D}_{3}$ (pro-vitD), was used at $100 \mathrm{nM}$ with or without pretreatment with $10 \mathrm{ng} / \mathrm{mL}$ of IFN- $\gamma$ for $2 \mathrm{~h}$. Bacterial killing was measured following incubation of the neutrophils with type 4 pneumococcal strains T4/T4R for $1 \mathrm{~h}$. The data shown represent the mean \pm SEM of 5 donors. ${ }^{*} p<0.05$,

\section{Results}

\section{Vitamin D Enhances Neutrophil Killing of}

S. pneumoniae

To investigate the effect of vitamin D on neutrophil killing of $S$. pneumoniae, neutrophils were stimulated with vitamin $\mathrm{D}$ (precursor $25(\mathrm{OH}) \mathrm{D}_{3}$ or active $\left.1,25(\mathrm{OH})_{2} \mathrm{D}_{3}\right)$, pneumococcal PGN or vitamin D combined with PGN for $6 \mathrm{~h}$. PGN, a Toll-like receptor 2 (TLR2) agonist [23], was used to investigate possible combinatorial effects of TLR signaling and the vitamin D
** $p<0.01$ by Mann-Whitney U test. c Neutrophils were incubated for $4 \mathrm{~h}$ in serum collected from patients with frequent respiratory tract infections $(n=12)$ with or without the addition of 100 $\mathrm{nM}$ of pro-vitD and challenged with T4R for $1 \mathrm{~h}$. Bacterial killing by neutrophils in the presence or absence of pro-vitD is depicted with columns showing the median with interquartile range for both groups. ${ }^{* *} p<0.01$ by Mann-Whitney U test. pathway. Vitamin D-stimulated neutrophils showed a significantly higher killing of the serotype 4 strain T4, its isogenic mutant in the capsule, T4R (Fig. 1a, b; online suppl. Table 1), and the serotype 2 strain D39 (online suppl. Fig. S2; online suppl. Table 1), as compared to the vehicle control. The capsular mutant T4R was more susceptible to neutrophil killing than encapsulated T4. Vitamin D combined with PGN further increased bacterial killing. Provitamin D had a basal effect, but when administered after IFN- $\gamma$ priming the microbicidal activity was similar to that of active vitamin $\mathrm{D}$. 

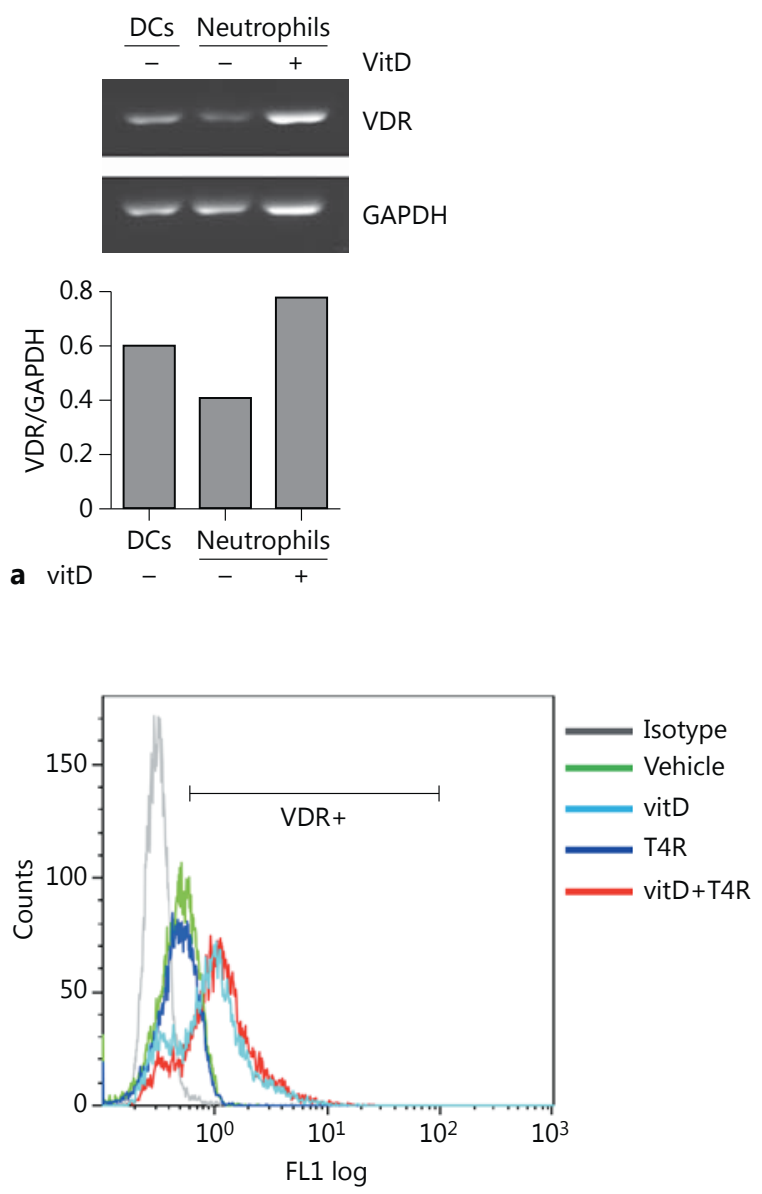

\begin{tabular}{|c|c|}
\hline Stimulation & \% positive cells \\
\hline Vehicle & 29.3 \\
\hline vitD & 71.6 \\
\hline T4R & 28.4 \\
\hline vitD+T4R & 81.2 \\
\hline
\end{tabular}
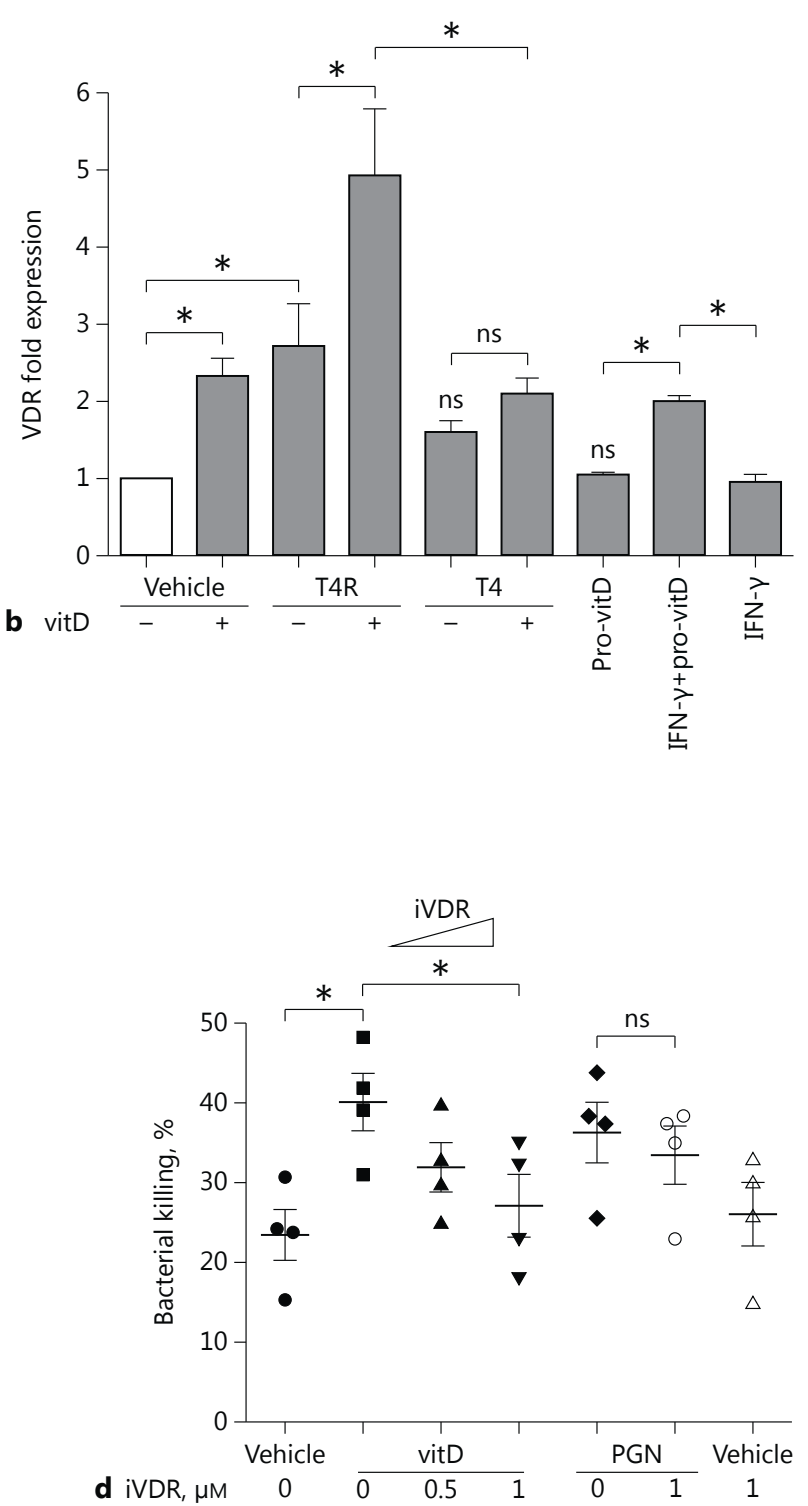

Fig. 2. Vitamin D and S. pneumoniae induce the VDR and the convertase CYP27B1 in neutrophils. a VDR and GAPDH (control) mRNA levels in human neutrophils and dendritic cells (DCs) left untreated or stimulated with $100 \mathrm{nM}$ of $1,25(\mathrm{OH})_{2} \mathrm{D}_{3}$ (vitD) for $2 \mathrm{~h}$ were analyzed by end-point RT-PCR. Bands were quantified densitometrically and normalized to GAPDH. $\mathbf{b}$ VDR expression in neutrophils pretreated with $100 \mathrm{nM}$ of $1,25(\mathrm{OH})_{2} \mathrm{D}_{3}$ (vitD) for $2 \mathrm{~h}$ and infected for $4 \mathrm{~h}$ with pneumococcal strains T4/T4R was measured by qPCR. The prohormone $25(\mathrm{OH}) \mathrm{D}_{3}$ (pro-vitD) was used at $100 \mathrm{nM}$ with or without pretreatment with $10 \mathrm{ng} / \mathrm{mL}$ of IFN- $\gamma$ for $2 h$. The data represent the mean gene expression normalized to GAPDH (fold-change compared to vehicle-treated cells) \pm SEM for 4 donors. c Flow cytometry analysis of VDR protein expression in vehicle or $100 \mathrm{nM}$ of $1,25(\mathrm{OH})_{2} \mathrm{D}_{3}$ (vitD)-stimulated neutrophils infected with pneumococci T4R for $4 \mathrm{~h}$. The cells were gated to exclude nonspecific binding using an isotypematched control antibody. The histograms are representative of 3 donors. The percentage of positive cells under different stimulations are quantified and shown in the table below. $\mathbf{d}$ Neutrophils were stimulated with $100 \mathrm{nM}$ of $1,25(\mathrm{OH})_{2} \mathrm{D}_{3}$ (vitD) or $10 \mu \mathrm{g} / \mathrm{mL}$ of PGN in the presence or absence of the iVDR ZK159222 (0-1 $\mu \mathrm{M})$ for $6 \mathrm{~h}$ and bacterial killing was measured upon incubation with T4R for $1 \mathrm{~h}$. The data shown represent the mean \pm SEM for 4 donors. ${ }^{*} p<0.05$ by Mann-Whitney $\mathrm{U}$ test. ns, not significant. 
To preclude any possible effects of other leukocytes, we compared the neutrophil killing of T4R with polymorphonuclear leukocytes (PBMCs) isolated from the same donor. Neutrophils induced higher killing of T4R than PBMCs (online suppl. Fig. S3A). This was not due to the viability of PBMCs since they robustly produced IL-6 upon infection with T4R (online suppl. Fig. S3B).

To investigate the clinical relevance of our findings, we studied the microbicidal activity of neutrophils incubated in human sera supplemented with vitamin D. Sera were collected from well-characterized patients with $>42$ days of symptoms from RTIs 12 months prior to study inclusion, but without an immunological diagnosis, in a previous study [10]. Neutrophils were incubated for $4 \mathrm{~h}$ with the sera upon supplementation with provitamin D (100 $\mathrm{nM}$ ) or vehicle, and challenged with T4R for $1 \mathrm{~h}$. Strikingly, vitamin D supplementation of sera boosted neutrophil killing of T4R compared to the vehicle control (Fig. 1c).

Vitamin D and S. pneumoniae Induce the VDR and the Convertase, CYP27B1, in Neutrophils

In order to explore mechanisms behind vitamin D-induced pneumococcal killing by neutrophils, we measured neutrophil expression of the VDR, which binds to vitamin D and the convertase CYP27B1, after the addition of vitamin D. Untreated neutrophils expressed basal levels of VDR, but at lower levels compared to dendritic cells, and could be induced by vitamin D (Fig. 2a). Stimulation with vitamin $\mathrm{D}$ caused a 2 -fold induction of VDR compared to vehicle control (Fig. 2b). When the pneumococcal strain T4R was added to vitamin D-treated neutrophils, a further increase in VDR was observed. The unencapsulated strain T4R induced higher VDR levels than the encapsulated T4 strain after vitamin D treatment (Fig. 2b). Vitamin D-mediated induction of VDR was also verified at the protein level by flow cytometry (Fig. 2c).

We then tested the effect of the addition of provitamin $\mathrm{D}$ and found no significant effect on the expression of VDR. However, when neutrophils were pretreated with IFN- $\gamma$, a proinflammatory cytokine that is upregulated during pneumonia in humans and mice [24], provitamin $\mathrm{D}$ induced significantly higher VDR expression (Fig. $2 \mathrm{~b})$. This could be due to IFN- $\gamma$-induced upregulation of the converting enzyme CYP27B1 (online suppl. Fig. S4A). Active vitamin $\mathrm{D}\left(1,25(\mathrm{OH})_{2} \mathrm{D}_{3}\right)$ did not induce CYP27B1, while vitamin D combined with T4R induced a 1.75-fold higher CYP27B1 expression compared to T4R alone (online suppl. Fig. S4B). Similar to VDR, CYP27B1

Vitamin D Modulates the Human

Neutrophil Response to S. pneumoniae expression was significantly increased when IFN- $\gamma$ was added prior to stimulation with provitamin D. Hence, our data suggest that IFN- $\gamma$ promotes intracrine activation of provitamin D in neutrophils and, combined with S. pneumoniae, induces upregulation of the vitamin $\mathrm{D}$ pathway genes, VDR and CYP27B1.

To further test if the observed enhanced pneumococcal killing induced by vitamin D was dependent on VDR, we employed the iVDR ZK159222 [25]. Inhibition of VDR blocked vitamin D-induced neutrophil killing of pneumococci in a dose-dependent manner (Fig. 2d). The VDR inhibitor did not affect pneumococcal killing by PGN-stimulated neutrophils, indicating its selective inhibition of the vitamin $\mathrm{D}$ pathway.

Vitamin D Induces Neutrophil Killing of Pneumococci by Upregulating Neutrophil Defensins

Neutrophils are known to express a large arsenal of antibacterial peptides (AMPs). HNP1-3 are the most abundant defensins in neutrophils, and we have previously shown that HNP1-3 from human neutrophil granular extract has direct microbicidal activity against pneumococci [26]. Hence, we investigated the effect of vitamin D on the induction and release of HNP1-3 by neutrophils. Vitamin D enhanced the transcription and release of HNP1-3 into the supernatant (Fig. 3a, b), which was further upregulated upon pneumococcal infection with T4, T4R or D39. The induction was VDR dependent since it could be blocked by the addition of the IVDR in a dose-dependent manner (Fig. 3c). To verify the cellular source of HNP1-3, we compared the release of HNP1-3 by neutrophils with PBMCs isolated from the same donor. Clearly, neutrophils were the major source of HNP1-3 (online suppl. Fig. S5A). In agreement with the elevated levels of HNP1-3, the culture supernatants of vitamin D-stimulated neutrophils also displayed an enhanced bacterial killing activity as compared to control neutrophil supernatants (online suppl. Fig. S5B). To test the importance of HNP1-3 in vitamin D-induced pneumococcal killing, we treated neutrophils with a monoclonal antibody against HNP1-3 prior to pneumococcal challenge, and found a significant reduction in vitamin $\mathrm{D}$-induced killing of T4R when compared to isotype antibody-treated cells (Fig. 3d). We also found that vitamin D promoted expression of the human cathelicidin LL-37 (online suppl. Fig. S5C).

We excluded the possibility that vitamin D-induced killing of pneumococci by neutrophils was due to enhanced bacterial uptake using FITC-labeled pneumococci and flow cytometry (online suppl. Fig. S6A), or NOS2 (nitric oxide synthase) production by neutrophils

J Innate Immun 2017;9:375-386

DOI: $10.1159 / 000455969$
379 


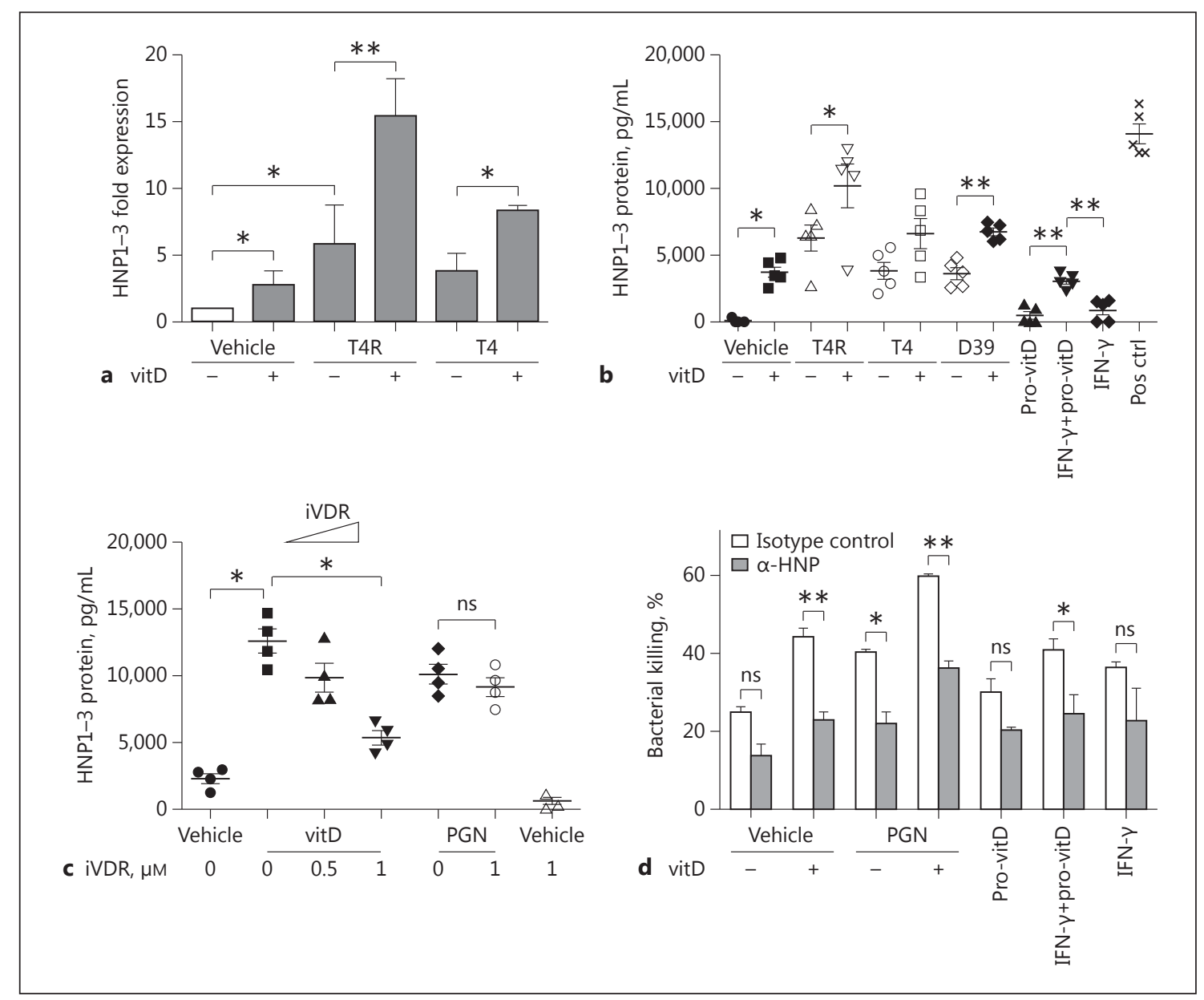

Fig. 3. Vitamin D induces neutrophil killing of pneumococci by upregulating neutrophil defensins. a Neutrophils were stimulated with vehicle $\left(0.1 \%\right.$ ethanol) or $100 \mathrm{nM}$ of $1,25(\mathrm{OH})_{2} \mathrm{D}_{3}$ (vitD) for $2 \mathrm{~h}$, followed by infection with pneumococcal strains T4, T4R, or D39 for $4 \mathrm{~h}$. HNP1-3 mRNA was measured by qPCR. The data shown represent the mean gene expression normalized to GAPDH (foldchange compared to vehicle-treated cells) \pm SEM for 3 donors. b HNP1-3 protein released into the neutrophil culture supernatants was quantified by ELISA. Neutrophils treated with the degranulation-inducing agents cytochalasin B $(5 \mu \mathrm{g} / \mathrm{mL})$ and fMLP $\left(10^{-7} \mathrm{M}\right)$ served as positive controls (Pos ctrl) for HNP ELISA. The proform $25(\mathrm{OH}) \mathrm{D}_{3}$ (pro-vitD) was used at $100 \mathrm{nM}$ with or without pretreat-

Fig. 4. Vitamin D priming of neutrophils downregulates inflammatory cytokine production and dampens apoptosis by upregulating IL-4. a, b Neutrophils were stimulated with vehicle $(0.1 \%$ ethanol) or $100 \mathrm{nM}$ of $1,25(\mathrm{OH})_{2} \mathrm{D}_{3}$ (vitD) for $2 \mathrm{~h}$ followed by infection with pneumococcal strains T4/T4R for $4 \mathrm{~h}$. The mRNA levels of TLR2 and NOD2 were measured by qPCR. The data shown represent the mean gene expression normalized to GAPDH (foldchange compared to vehicle-treated cells) \pm SEM for 4 donors. c, d Flow cytometry analysis of TLR2 and NOD2 protein expression in vehicle or $100 \mathrm{nM}$ of vitD-stimulated neutrophils infected with pneumococci T4R for $4 \mathrm{~h}$. The cells were gated to exclude nonspe- ment with $10 \mathrm{ng} / \mathrm{mL}$ of IFN- $\gamma$ for $2 \mathrm{~h}$. The data shown represent the mean \pm SEM for 5 donors. ${ }^{*} p<0.05,{ }^{* *} p<0.01$ by Mann-Whitney U test. c Effect of iVDR ZK159222 $(0.5-1 \mu \mathrm{M})$ on HNP release by neutrophils stimulated with $100 \mathrm{nM}$ of $1,25(\mathrm{OH})_{2} \mathrm{D}_{3}$ (vitD) or $10 \mu \mathrm{g} /$ $\mathrm{mL}$ of PGN for $4 \mathrm{~h}$. The data shown represent the mean \pm SEM for 4 donors. ${ }^{*} p<0.05$ by Mann-Whitney $\mathrm{U}$ test. $\mathbf{d}$ Neutrophils pretreated with anti-HNP1-3 ( $\alpha-\mathrm{HNP} ; 0.5 \mu \mathrm{g} / \mathrm{mL}$ ) or isotype antibodies were stimulated as indicated and bacterial killing was measured upon incubation with T4R. Pro-vitD was used at $100 \mathrm{nM}$ with or without pretreatment with $10 \mathrm{ng} / \mathrm{mL}$ of IFN- $\gamma$ for $2 \mathrm{~h}$. The data shown represent the mean \pm SEM for 3 donors. ${ }^{*} p<0.05,{ }^{* *} p<0.01$ by 2 -way ANOVA with Bonferroni post hoc test. ns, not significant.

cific binding using an isotype-matched control antibody. The histograms are representative of 3 donors. The percentages of positive cells under different stimulations were quantified and shown in the table below. e, f Neutrophil supernatants were analyzed for IL-6 and IL- 4 by ELISA. LPS ( $10 \mathrm{ng} / \mathrm{mL})$ was used as a positive control (Pos ctrl) for the IL-6 ELISA. The data shown represent the mean \pm SEM for 4 donors. $g$ Neutrophil apoptosis was measured by flow cytometry analysis of Annexin $\mathrm{V}$-stained cells at $4 \mathrm{~h}$ postinfection with T4/T4R. The data shown represent the mean \pm SEM for 4 donors. ${ }^{*} p<0.05$ by Mann-Whitney U test. ns, not significant.

(For figure see next page.)
Subramanian/Bergman/ Henriques-Normark 


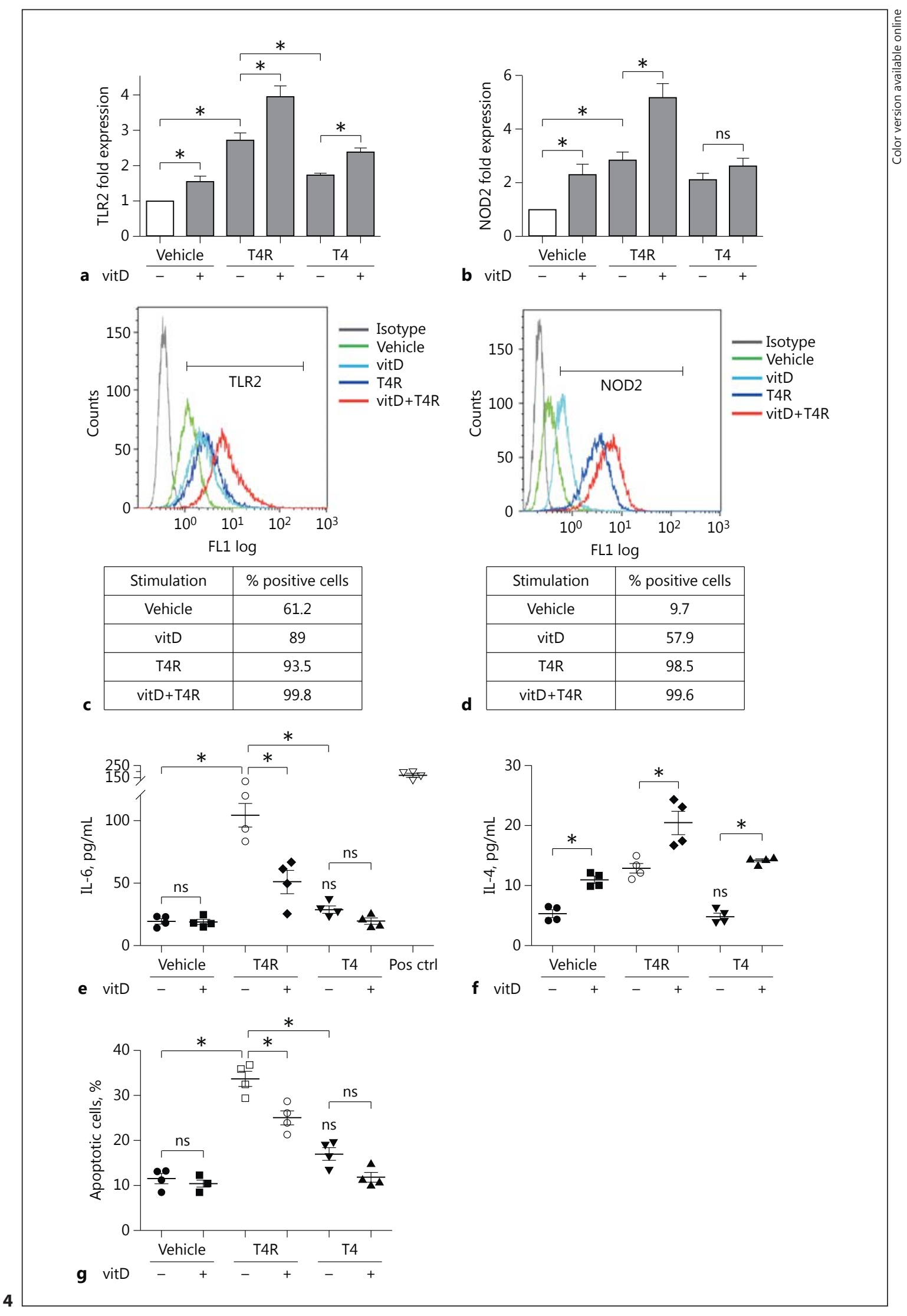


upon challenge with pneumococci (online suppl. Fig. S6B), or oxidative burst by measuring the production of ROS (reactive oxygen species) using CellROX green, and by inhibiting ROS using the NADPH oxidase inhibitor diphenyleiodonium chloride (online Suppl. Fig. S6C, D). Also, we measured neutrophil extracellular trap-associated elastase activity in the culture supernatants and found no significant increase in the presence of vitamin D (online suppl. Fig. S6E). In summary, our results show that vitamin D induces the AMPs HNP1-3 and LL-37 in neutrophils, promoting the killing of pneumococci.

\section{Vitamin D Priming of Neutrophils Downregulates}

Inflammatory Cytokine Production and Dampens

Apoptosis by Upregulating IL-4

TLR2 and NOD2 are cell membrane pattern receptors shown to be important for pneumococcal recognition by immune cells [27]. We found that TLR2 and NOD2 mRNA (Fig. 4a, b) and proteins (Fig. 4c, d) were induced in vitamin $\mathrm{D}$-primed neutrophils, and the addition of pneumococci further upregulated TLR2 and NOD2 as compared to controls. Despite the induction of these receptors, we found that vitamin D priming of neutrophils prior to pneumococcal infection significantly reduced the levels of proinflammatory cytokines IL-6, IL-8, and IL12 p70 in the culture supernatants (Fig. 4e; online suppl. Fig. S7A, B), and enhanced production of the anti-inflammatory cytokine IL-4 (Fig. 4f) after $6 \mathrm{~h}$ of total culture. This trend was consistent and sustained even after overnight $(22 \mathrm{~h})$ postincubation with heat-killed pneumococci (online suppl. Fig. S7C, D).

Since increased IL-4 production can downregulate apoptosis [28], we next investigated the effect of vitamin D on neutrophil apoptosis upon pneumococcal infection. Vitamin D-primed neutrophils exhibited a significantly lower percentage of apoptotic cells upon T4R infection (Fig. 4g), and T4R induced higher apoptosis than T4. Time-course analysis showed that vitamin D-stimulated neutrophils underwent a steady rate of apoptosis upon infection, although at a slower rate than controls (online suppl. Fig. S7E). Since neutrophils express the IL-4 receptor [29], we investigated whether vitamin D-induced IL-4 production by neutrophils can affect apoptosis of pneumococcal-infected neutrophils. The addition of IL-4 (20 $\mathrm{ng} / \mathrm{mL}$ ) reduced the percentage of apoptotic cells upon T4R infection and vitamin D combined with IL-4 further reduced apoptosis (online suppl. Fig. S7F). Neutrophils stimulated with the apoptotic inhibitor G-CSF $(20 \mathrm{ng} / \mathrm{mL})$ served as negative controls. Thus, vitamin $\mathrm{D}$ modulates neutrophil cytokine responses to pneumococci by dampening excessive inflammatory cytokine production and promoting anti-inflammatory IL-4 production, leading to the downregulation of inflammation and apoptosis.

\section{Vitamin D-Primed Neutrophils Upregulate SOCS-1} and SOCS-3 and Downregulate TRAF6 Causing $N F-\kappa B$ Suppression in Response to Pneumococci

To decipher the mechanism of vitamin D-mediated suppression of inflammatory cytokines, we measured the expression of negative regulators of TLR signalling and cytokine production by qPCR (Fig. 5a, b; online suppl. Fig. S8A). We found that vitamin D specifically upregulated the suppressor of cytokine signaling (SOCS) proteins, SOCS-1 (Fig. 5a) and SOCS-3 mRNA (Fig. 5b). Interestingly, IL-4, which was induced by vitamin $\mathrm{D}$, also upregulated SOCS-1 and SOCS-3 mRNA. Consistent with the mRNA data, vitamin D and IL-4 caused a significant upregulation of SOCS-1 and SOCS-3 proteins (Fig. 5c). However, the level of another negative regulatory protein, A20, also known as tumor necrosis factoralpha-induced protein 3, remained unaffected (online suppl. Fig. S8B), implicating a specific regulation of SOCS-1 and SOCS-3 by vitamin D. Moreover, we found that vitamin $\mathrm{D}$ and IL-4 stimulation reduced phosphorylation of the NF- $\kappa B$ inhibitor I $\kappa B a$, thereby stabilizing the levels of IkBa in neutrophils (Fig. 5c).

Blocking IL-4 using a specific antibody decreased vitamin D-induced SOCS-1 expression (Fig. 5d). Also, addition of the VDR antagonist reduced vitamin $\mathrm{D}$-induced SOCS-1 upregulation. Consequently, we found that the TLR adaptor TRAF6 was downregulated in vitamin D- or IL-4-stimulated neutrophils, and this was counteracted by blocking VDR or IL-4 (Fig. 5d).

TLR signaling pathways result in translocation of NF$\kappa B$ to the nucleus to induce production of inflammatory cytokines. We performed cell fractionation studies followed by Western blotting to measure nuclear NF-кBp65 upon T4R infection with or without vitamin $\mathrm{D}$ priming. Concomitant with higher levels of the NF- $\kappa \mathrm{B}$-inhibitor I $\kappa \mathrm{B} \alpha$ (Fig. 5c), we found a reduction of nuclear NF- $\kappa \mathrm{Bp} 65$ in vitamin $\mathrm{D}$ - or IL-4-primed neutrophils (Fig. 5e) compared to T4R-infected controls. The inhibition of VDR or IL-4 restored levels of nuclear NF- $\kappa B p 65$ similar to those of the T4R-infected controls. Our data show that in response to pneumococci, vitamin D upregulates SOCS-1 and SOCS-3 in neutrophils, leading to the downregulation of TRAF6 and suppression of NF- $\kappa B$ nuclear translocation, thereby limiting excessive inflammatory cytokine production.
382

J Innate Immun 2017;9:375-386

DOI: $10.1159 / 000455969$
Subramanian/Bergman/

Henriques-Normark 


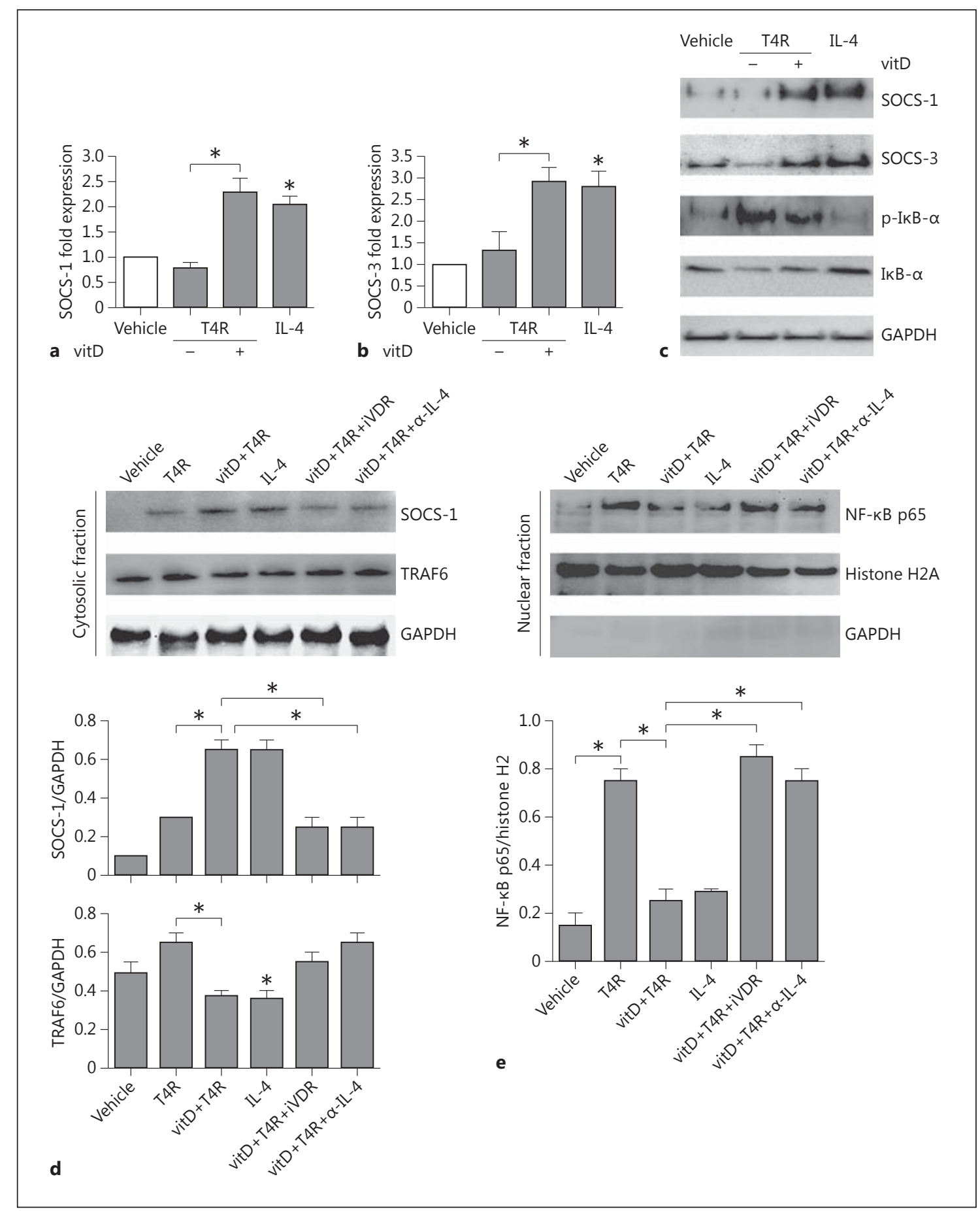

Fig.5. Vitamin D-primed neutrophils upregulate SOCS-1 and SOCS3 and downregulate TRAF6, causing NF- $\kappa$ B suppression, in response to pneumococci. a, b Neutrophils were infected with T4R for $2 \mathrm{~h}$ with or without pretreatment with $100 \mathrm{nM}$ of $1,25(\mathrm{OH})_{2} \mathrm{D}_{3}$ (vitD) for $2 \mathrm{~h}$ and the mRNA levels of SOCS-1 (a) and SOCS-3 (b) were measured by qPCR. Human IL-4 (20 ng/mL) was used as a control. c Vehicleor vitamin D-pretreated neutrophils were infected with T4R for $2 \mathrm{~h}$

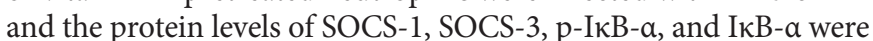
measured by immunoblotting. GAPDH was used as a loading con- trol. d, e Cytosolic and nuclear fractions were isolated from T4Rinfected neutrophils pretreated with vehicle or $100 \mathrm{nM}$ of vitD for $2 \mathrm{~h}$. In control wells, IL-4-neutralizing antibody $(0.1 \mu \mathrm{g} / \mathrm{mL})$ or iVDR (1 $\mu \mathrm{M}$ of ZK159222) were added. The cytosolic fraction (d) was probed for SOCS-1 and TRAF- 6 and the nuclear fraction (e) was probed for NF- $\mathrm{kB}$ (p65). Histone H2A and GAPDH served as loading controls for the nuclear and cytosolic fractions, respectively. Bottom bands were quantified densitometrically and normalized to the respective loading controls. ${ }^{*} p<0.05$ by Mann-Whitney $\mathrm{U}$ test.
Vitamin D Modulates the Human Neutrophil Response to S. pneumoniae
J Innate Immun 2017;9:375-386 DOI: $10.1159 / 000455969$ 


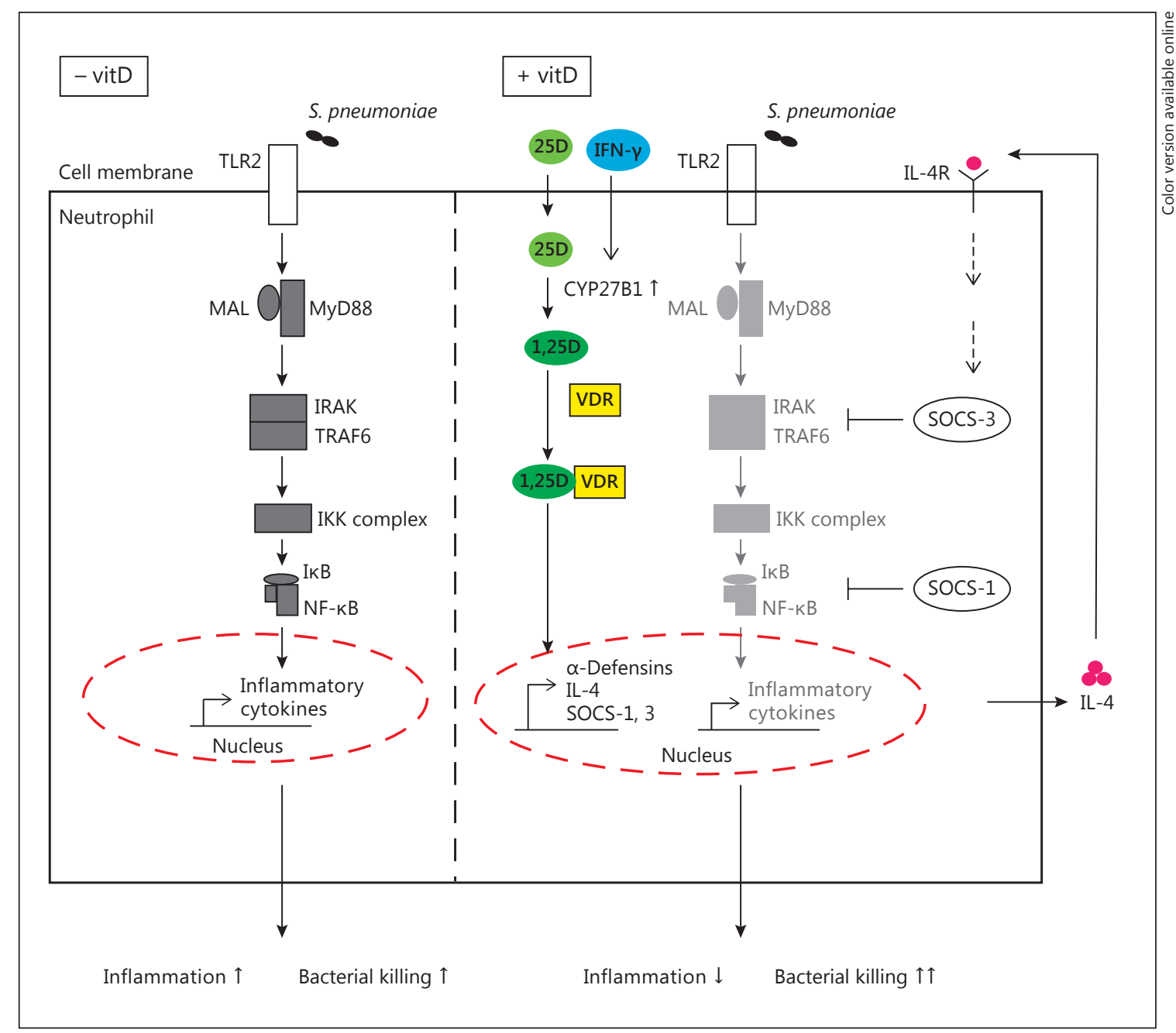

Fig. 6. Potential mechanisms involved in vitamin D-mediated immunomodulation of neutrophils. Infection with S. pneumoniae stimulates TLR2 on neutrophils leading to the production of proinflammatory cytokines via the NF- $\kappa \mathrm{B}$ signaling pathway. In the presence of IFN- $\gamma$, neutrophils upregulate the converting enzyme CYP27B1, which mediates intracrine activation of provitamin D and the VDR, resulting in the upregulation of alpha-defensins
(HNP1-3), which mediate killing of pneumococci. Moreover, vitamin D also induces the SOCS proteins SOCS-1 and SOCS-3 in an IL-4-dependent manner, leading to the downregulation of TRAF6 and NF- $\kappa B$, thereby regulating the excessive production of inflammatory cytokines. Hence, vitamin D simultaneously improves the neutrophil killing of pneumococci, while limiting excessive inflammation.

\section{Discussion}

Vitamin D deficiency is associated with a range of bacterial infections [30] in humans, particularly with pneumonia [15]. However, the effects of vitamin D on neutrophils, which are the major inflammatory cells during pneumococcal infections, remain largely unknown. Here, we have shown that vitamin $\mathrm{D}$ enhances pneumococcal killing by neutrophils and identified alpha-defensins (HNP1-3) as mediators of the antibacterial activity besides the previously known vitamin $\mathrm{D}$-responsive AMP cathelicidin (LL-37) [31]. We found that HNP1-3 are important for vitamin D-induced killing, since blocking antibodies abrogate killing. Importantly, vitamin D supplementation of sera with different vitamin D levels (mean $84 \mathrm{nM}$ in our experiments), collected from patients with increased susceptibility to bacterial RTIs, boosted pneumococcal killing by neutrophils. This is relevant for clinical practice, since a general notion is that the potential beneficial effect levels out at presupplementation vitamin $\mathrm{D}$ levels of $50 \mathrm{nM}$. However, the evidence for $50 \mathrm{nM}$ is based on bone health and it is likely that the cutoff for 
beneficial effects against infections is higher. For example, Science et al. [32] showed that children with levels below $75 \mathrm{nM}$ have a higher risk of RTIs than those with levels above $75 \mathrm{nM}$. In addition, Sabetta et al. [33] found that $95 \mathrm{nM}$ was the cutoff for beneficial affects against viral RTIs. Currently, there is no conclusive evidence or available guidelines for vitamin $\mathrm{D}$ supplementation to prevent RTIs and thus future clinical interventional trials are needed to clarify this issue.

We have shown that in response to vitamin $\mathrm{D}$, neutrophils upregulate the converting enzyme CYP27B1 and the receptor VDR, which are further upregulated upon pneumococcal infection, particularly with the capsular mutant strain T4R. The higher effect of T4R could be because the capsule in wild-type pneumococci masks TLR ligands [34], and thereby impedes recognition by neutrophils. The proform of vitamin D had basal effects, but was enhanced by pretreatment with IFN- $\gamma$. This implies that the proform may require a trigger, such as microbial invasion (TLR activation) or inflammation (higher IFN- $\gamma$ ) to enable its intracrine activation, and thereby mediate downstream effects via VDR signaling. In agreement with our results, VDR binding sites have been found within the promoter of HNP1-3 in a promoter analysis study [35]. Also, our results explain the low levels of HNP1-3 found in vitamin $\mathrm{D}$-deficient asthma patients, which can be restored upon vitamin D supplementation [36].

Furthermore, vitamin D combined with pneumococcal PGN enhanced neutrophil killing of pneumococci, suggesting possible combinatorial effects of TLR signaling with the vitamin D pathway. Interestingly, we found that vitamin $\mathrm{D}$ downregulates the production of proinflammatory cytokines IL-6, IL-8, and IL-12, and upregulates the anti-inflammatory cytokine IL-4 in neutrophils infected with pneumococci. Our data are in agreement with a previous study showing infiltration of IL-4-ex- pressing neutrophils in the skin of psoriatic patients upon exposure to UVB rays, which triggers vitamin D synthesis [37]. High levels of IL- 6 and low levels of IL- 4 have also been shown to positively correlate to disease severity scores, and are valid indicators of prognosis in patients with community-acquired pneumonia [38, 39]. Also, we showed that vitamin $\mathrm{D}$ upregulates the pattern recognition receptors TLR2 and NOD2, but also induces the negative regulators of TLR-induced inflammation, SOCS-1 and SOCS-3, in an IL4-dependent manner. This results in reduction of I $\mathrm{B}$ phosphorylation and the TLR adaptor TRAF6, leading to suppression of NF- $\kappa$ B nuclear translocation (Fig. 6).

In conclusion, our results suggest that vitamin $\mathrm{D}$ can limit excessive inflammation while boosting the antipneumococcal activity of neutrophils, making vitamin D a promising candidate for treatment of pneumococcal infections alongside antibiotics. Further clinical studies are warranted to evaluate the usefulness of vitamin $\mathrm{D}$ for patients with pneumococcal diseases.

\section{Acknowledgements}

We thank Dr. Susan Farmand, Karolinska Institutet, Stockholm for providing protocols to isolate human neutrophils and Ilias Galanis, statistician at the Public Health Agency of Sweden, for help with statistics. We also thank Dr. Arndt Schmitz and Dr. Andreas Steinmeyer, Bayer Pharma AG, Berlin, Germany, for providing the VDR antagonist ZK159222.

This work was supported by grants from the Swedish Research Council, ALF grant from Stockholm County Council, the Swedish Foundation for Strategic research (SSF), and Knut and Alice Wallenberg foundation.

\section{Disclosure Statement}

The authors have no financial conflicts of interest.

\section{References}

1 Black RE, Cousens S, Johnson HL, Lawn JE, Rudan I, Bassani DG, Jha P, Campbell H, Walker CF, Cibulskis R, Eisele T, Liu L, Mathers C: Global, regional, and national causes of child mortality in 2008: a systematic analysis. Lancet 2010;375:1969-1987.

2 Wartha F, Beiter K, Albiger B, Fernebro J, Zychlinsky A, Normark S, Henriques-Normark B: Capsule and D-alanylated lipoteichoic acids protect Streptococcus pneumoniae against neutrophil extracellular traps. Cell Microbiol 2007;9:1162-1171.

Vitamin D Modulates the Human

Neutrophil Response to S. pneumoniae
3 Hyams C, Camberlein E, Cohen JM, Bax K, Brown JS: The Streptococcus pneumoniae capsule inhibits complement activity and neutrophil phagocytosis by multiple mechanisms. Infect Immun 2010;78:704-715.

4 Craig A, Mai J, Cai S, Jeyaseelan S: Neutrophil recruitment to the lungs during bacterial pneumonia. Infect Immun 2009;77:568-575.

5 Garvy BA, Harmsen AG: The importance of neutrophils in resistance to pneumococcal pneumonia in adult and neonatal mice. Inflammation 1996;20:499-512.
6 Zasloff M: Antimicrobial peptides of multicellular organisms. Nature 2002;415:389395.

7 Kim C, Kaufmann SH: Defensin: a multifunctional molecule lives up to its versatile name. Trends Microbiol 2006;14:428-431.

8 Pletz MW, Terkamp C, Schumacher U, Rohde G, Schutte H, Welte T, Bals R: Vitamin D deficiency in community-acquired pneumonia: low levels of 1,25(OH)2 D are associated with disease severity. Respir Res 2014;15:53. 
9 de Sa Del Fiol F, Barberato-Filho S, Lopes LC, de Cassia Bergamaschi C: Vitamin D and respiratory infections. J Infect Dev Ctries 2015; 9:355-361.

10 Bergman P, Norlin AC, Hansen S, Rekha RS, Agerberth B, Bjorkhem-Bergman L, Ekstrom L, Lindh JD, Andersson J: Vitamin $\mathrm{D}_{3}$ supplementation in patients with frequent respiratory tract infections: a randomised and double-blind intervention study. BMJ Open 2012; 2:e001663.

11 Hewison M: Antibacterial effects of vitamin D. Nat Rev Endocrinol 2011;7:337-345.

12 Liu PT, Stenger S, Li H, Wenzel L, Tan BH, Krutzik SR, Ochoa MT, Schauber J, Wu K, Meinken C, Kamen DL, Wagner M, Bals R, Steinmeyer A, Zugel U, Gallo RL, Eisenberg D, Hewison M, Hollis BW, Adams JS, Bloom BR, Modlin RL: Toll-like receptor triggering of a vitamin D-mediated human antimicrobial response. Science 2006;311:1770-1773.

13 Olliver M, Spelmink L, Hiew J, Meyer-Hoffert $\mathrm{U}$, Henriques-Normark B, Bergman P: Immunomodulatory effects of vitamin D on innate and adaptive immune responses to Streptococcus pneumoniae. J Infect Dis 2013;208: 1474-1481.

14 Cantorna MT, Snyder L, Lin YD, Yang L: Vitamin $\mathrm{D}$ and $1,25(\mathrm{OH})_{2} \mathrm{D}$ regulation of $\mathrm{T}$ cells. Nutrients 2015;7:3011-3021

15 Holter JC, Ueland T, Norseth J, Brunborg C, Froland SS, Husebye E, Aukrust P, Heggelund L: Vitamin D status and long-term mortality in community-acquired pneumonia: secondary data analysis from a prospective cohort. PLoS One 2016;11:e0158536.

16 Eisenhauer PB, Lehrer RI: Mouse neutrophils lack defensins. Infect Immun 1992;60:34463447.

17 Glenthoj A, Dahl S, Larsen MT, Cowland JB, Borregaard N: Human alpha-defensin expression is not dependent on CCAAT/enhancer binding protein-epsilon in a murine model. PLoS One 2014;9:e92471.

18 Gombart AF, Borregaard N, Koeffler HP: Human cathelicidin antimicrobial peptide (CAMP) gene is a direct target of the vitamin $\mathrm{D}$ receptor and is strongly up-regulated in myeloid cells by 1,25 -dihydroxyvitamin $\mathrm{D}_{3}$. FASEB J 2005;19:1067-1077.

19 Tettelin H, Nelson KE, Paulsen IT, et al: Complete genome sequence of a virulent isolate of Streptococcus pneumoniae. Science 2001;293: 498-506.
20 Fernebro J, Andersson I, Sublett J, Morfeldt E, Novak R, Tuomanen E, Normark S, Normark BH: Capsular expression in Streptococcus pneumoniae negatively affects spontaneous and antibiotic-induced lysis and contributes to antibiotic tolerance. J Infect Dis 2004;189: 328-338.

21 Lanie JA, Ng WL, Kazmierczak KM, Andrzejewski TM, Davidsen TM, Wayne KJ, Tettelin $\mathrm{H}$, Glass JI, Winkler ME: Genome sequence of Avery's virulent serotype 2 strain D39 of Streptococcus pneumoniae and comparison with that of unencapsulated laboratory strain R6. J Bacteriol 2007;189:38-51.

22 Gomez-Alonso C, Naves-Diaz ML, Fernandez-Martin JL, Diaz-Lopez JB, FernandezCoto MT, Cannata-Andia JB: Vitamin D status and secondary hyperparathyroidism: the importance of 25-hydroxyvitamin D cut-off levels. Kidney Int Suppl 2003;85:S44-S48.

23 Komori M, Nakamura Y, Ping J, Feng L, Toyama K, Kim Y, Ferrieri P, Lin J: Pneumococcal peptidoglycan-polysaccharides regulate Toll-like receptor 2 in the mouse middle ear epithelial cells. Pediatr Res 2011;69:101105.

24 Mitchell AJ, Yau B, McQuillan JA, Ball HJ, Too LK, Abtin A, Hertzog P, Leib SL, Jones CA, Gerega SK, Weninger W, Hunt NH: Inflammasome-dependent IFN- $\gamma$ drives pathogenesis in Streptococcus pneumoniae meningitis. J Immunol 2012;189:4970-4980.

25 Lamblin M, Spingarn R, Wang TT, Burger MC, Dabbas B, Moitessier N, White JH, Gleason JL: An $o$-aminoanilide analogue of 1a,25dihydroxyvitamin $\mathrm{D}_{3}$ functions as a strong vitamin D receptor antagonist. J Med Chem 2010;53:7461-7465.

26 Beiter K, Wartha F, Hurwitz R, Normark S, Zychlinsky A, Henriques-Normark B: The capsule sensitizes Streptococcus pneumoniae to $a$-defensins human neutrophil proteins 1 to 3. Infect Immun 2008;76:3710-3716.

27 Koppe U, Suttorp N, Opitz B: Recognition of Streptococcus pneumoniae by the innate immune system. Cell Microbiol 2012;14:460466.

28 Lemaire C, Andréau K, Fraisse CS, Adam A, Souvannavong V: IL-4 inhibits apoptosis and prevents mitochondrial damage without inducing the switch to necrosis observed with caspase inhibitors. Cell Death Differ 1999;6: 813-820.

29 Futosi K, Fodor S, Mocsai A: Neutrophil cell surface receptors and their intracellular signal transduction pathways. Int Immunopharmacol 2013;17:638-650.
30 Zittermann A, Pilz S, Hoffmann H, Marz W: Vitamin D and airway infections: a European perspective. Eur J Med Res 2016;21:14.

31 Liu PT, Stenger S, Tang DH, Modlin RL: Cutting edge: vitamin $\mathrm{D}$-mediated human antimicrobial activity against Mycobacterium tuberculosis is dependent on the induction of cathelicidin. J Immunol 2007;179:2060-2063.

32 Science M, Maguire JL, Russell ML, Smieja M, Walter SD, Loeb M: Low serum 25-hydroxyvitamin D level and risk of upper respiratory tract infection in children and adolescents. Clin Infect Dis 2013;57:392-397.

33 Sabetta JR, DePetrillo P, Cipriani RJ, Smardin J, Burns LA, Landry ML: Serum 25-hydroxyvitamin $\mathrm{D}$ and the incidence of acute viral respiratory tract infections in healthy adults. PLoS One 2010;5:e11088.

34 de Vos AF, Dessing MC, Lammers AJ, de Porto AP, Florquin S, de Boer OJ, de Beer R, Terpstra S, Bootsma HJ, Hermans PW, van 't Veer C, van der Poll T: The polysaccharide capsule of Streptococcus pneumoniae partially impedes MyD88-mediated immunity during pneumonia in mice. PLoS One 2015;10: e0118181.

35 Brahmachary M, Schonbach C, Yang L, Huang E, Tan SL, Chowdhary R, Krishnan SP, Lin CY, Hume DA, Kai C, Kawai J, Carninci P, Hayashizaki Y, Bajic VB: Computational promoter analysis of mouse, rat and human antimicrobial peptide-coding genes. BMC Bioinformatics 2006;7(suppl 5):S8

36 Thijs W, Janssen K, Verhoosel RM, Papapoulos SE, Le Cessie S, Middeldorp S, Melissant CF, Rabe KF, Hiemstra PS: Effect of vitamin $\mathrm{D}$ treatment on antimicrobial peptides in asthma patients and healthy controls. Eur Respir J 2011;38:4888.

37 Piskin G, Tursen U, Bos JD, Teunissen MB: IL-4 expression by neutrophils in psoriasis lesional skin upon high-dose UVB exposure. Dermatology 2003;207:51-53.

38 Fernandez-Serrano S, Dorca J, Coromines M, Carratala J, Gudiol F, Manresa F: Molecular inflammatory responses measured in blood of patients with severe community-acquired pneumonia. Clin Diagn Lab Immunol 2003; 10:813-820.

39 Martinez R, Menendez R, Reyes S, Polverino E, Cilloniz C, Martinez A, Esquinas C, Filella $\mathrm{X}$, Ramirez P, Torres A: Factors associated with inflammatory cytokine patterns in community-acquired pneumonia. Eur Respir J 2011;37:393-399. 